\title{
Serum Soluble Interleukin-2 Receptor Is a Biomarker for Pneumocystis jirovecii Pneumonia among Patients with Rheumatoid Arthritis under Methotrexate Therapy
}

\author{
Noriho Sakamoto, ${ }^{1}$ Shintaro Hara, ${ }^{1,2}$ Hiroshi Ishimoto, ${ }^{1}$ Shota Nakashima, ${ }^{1}$ \\ Hirokazu Yura, ${ }^{1}$ Takuto Miyamura, ${ }^{1}$ Daisuke Okuno, ${ }^{1}$ Atsuko Hara, ${ }^{1}$ \\ Tomoyuki Kakugawa, ${ }^{1}$ Hiroyuki Yamaguchi, ${ }^{1}$ Yasushi Obase, ${ }^{1}$ Hisako Kushima, ${ }^{3}$ \\ Hiroshi Ishii, ${ }^{3}$ Shingo Noguchi, ${ }^{4}$ Takashi Kido, ${ }^{4}$ Tsutomu Kobayashi, ${ }^{5}$ \\ Yoshifumi Soejima, ${ }^{5}$ Sumako Yoshioka, ${ }^{6}$ Yuji Ishimatsu, ${ }^{7}$ Kazuhiro Yatera, ${ }^{4}$ \\ Jun-ichi Kadota ${ }^{8}$ and Hiroshi Mukae ${ }^{1}$

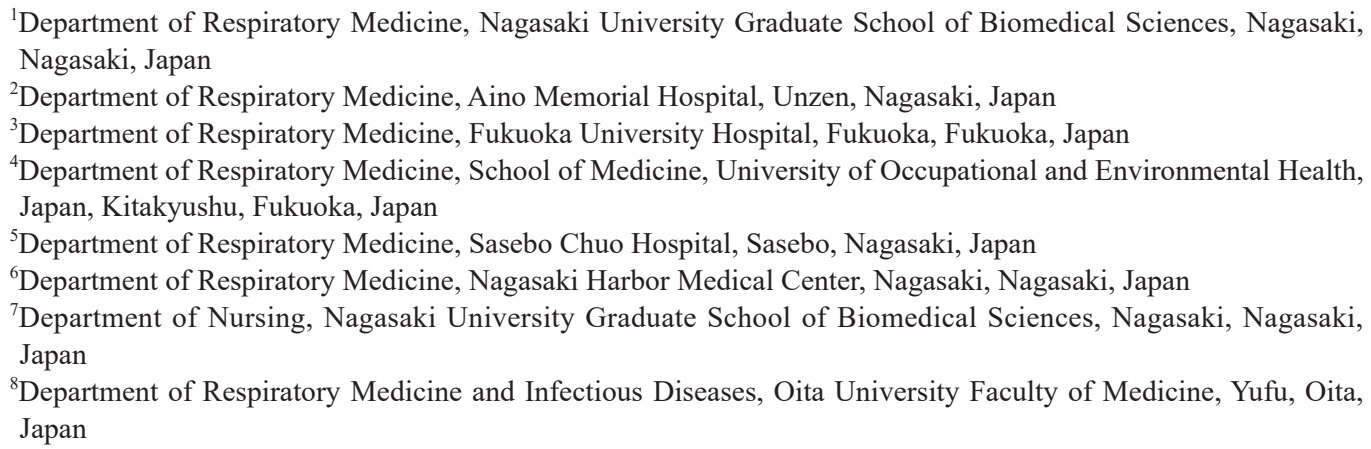

Rheumatoid arthritis (RA) is a chronic autoimmune disease characterized by systemic joint inflammation and may manifest as interstitial pneumonia (IP). Methotrexate (MTX) is one of the main therapeutic drugs used for RA, but MTX could cause severe side effects, including Pneumocystis jirovecii pneumonia (PCP) and IP. Owing to similar symptoms, it is sometimes difficult to discriminate MTX therapy-associated PCP (MTX-PCP) and MTX therapy-associated IP (MTX-IP). Soluble interleukin-2 receptor (sIL-2R) is considered a marker of T-cell activation, and serum sIL-2R levels are elevated in RA and PCP. This led us to hypothesize that serum sIL-2R is a potential biomarker for discriminating MTX-PCP and MTX-IP. Accordingly, we carried out a retrospective analysis of 20 MITX-PCP cases, 30 MTX-IP cases, and as controls, 16 patients with RA-associated IP (RA-IP) and 13 patients with PCP without MTX treatment (PCP group). C-reactive protein and alveolar-arterial oxygen differences were higher in the MTX-PCP group than those in the RA-IP and MTX-IP groups. Importantly, serum levels of sIL-2R in MTX-PCP were significantly higher than those in other three groups. Based on the receiver operating characteristic curve, the cut-off level of sIL-2R resulting in the highest diagnostic accuracy for MTX-PCP was $1,311.5 \mathrm{U} / \mathrm{mL}$, discriminating between MTX-PCP and other groups with $91.7 \%$ sensitivity and $78.6 \%$ specificity. Thus, patients with MTX-PCP show a higher degree of systemic inflammation, severe hypoxemia, and increased sIL-2R levels compared with those in MTX-IP cases. In conclusion, serum sIL-2R could be a biomarker for PCP diagnosis among patients with RA under MTX therapy.

Keywords: drug-induced pneumonia; interleukin-2 receptor; methotrexate; Pneumocystis jirovecii pneumonia; rheumatoid arthritis

Tohoku J. Exp. Med., 2019 July, 248 (3), 209-216. C 2019 Tohoku University Medical Press

Introduction

Rheumatoid arthritis (RA) is a chronic autoimmune disease characterized by systemic joint inflammation. Although there are a large number of therapeutic resources available for the treatment of RA, methotrexate (MTX) is

Received March 28, 2019; revised and accepted July 10, 2019. Published online July 31, 2019; doi: 10.1620/tjem.248.209.

Correspondence: Noriho Sakamoto, M.D., Ph.D., Department of Respiratory Medicine, Nagasaki University Graduate School of Biomedical Sciences, 1-7-1 Sakamoto, Nagasaki, Nagasaki 852-8501, Japan.

e-mail: nsakamot@nagasaki-u.ac.jp 
one of the main drugs used against this disease (Singh et al. 2016; Smolen et al. 2017). MTX has multiple mechanisms of action that alleviate clinical symptoms in patients with RA, including the inhibition of inflammatory cell proliferation, interference with $\mathrm{T}$ cell activity, and cytokine secretion (Chan and Cronstein 2002). Despite this, MTX therapy is not always the best choice as it can have several side effects such as liver enzyme abnormalities, alopecia, gastrointestinal events, hematological events, hypertension, infection, interstitial pneumonia, mucocutaneous events, myocardial infarction, and rashes (Lopez-Olivo et al. 2014). From the view of pulmonary involvement, MTX treatment can induce interstitial pneumonia (MTX-IP) and can be a risk factor for Pneumocystis jirovecii pneumonia (PCP) (Hashimoto et al. 2017). Meanwhile, RA-associated interstitial pneumonia (RA-IP) is a well-known manifestation of RA and its prevalence has been reported to be between 4 and 50\% (Zou et al. 2012; Norton et al. 2013; Richman et al. 2013). In the clinical setting, RA-IP, MTX-IP, and PCP, and especially PCP developed during MTX treatment (MTX-PCP), are sometimes hard to distinguish.

The interleukin-2 receptor (IL-2R) complex is comprised of $\alpha$ (CD25), $\beta$ (CD122), and common $\gamma$ (CD132) chains expressed on the surface of T cells (Turka and Walsh 2008). Of these, IL-2R $\alpha$ expression is increased with $T$ cell activation. IL-2R $\alpha$ is released by $\mathrm{T}$ cells as a soluble form and is called soluble IL-2 receptor (sIL-2R). Serum sIL-2R is considered a marker of T-cell activation (Rubin and Nelson 1990), and it has been reported as a marker for diseases such as cancer, infections, drug-induced side effects, and autoimmune inflammation including RA and PCP (Reddy and Grieco 1988; Rubin and Nelson 1990; Takahashi et al. 1991; Tanaka et al. 2002; Chodorowska et al. 2003; Witkowska 2005; Thi Hong Nguyen et al. 2017). However, whether sIL-2R can be used as a marker for patients with MTX-PCP and MTX-IP has not been investigated. In the present study, we examined the potential use of serum sIL-2R as a marker to differentiate between MTX-IP and MTX-PCP.

\section{Methods}

\section{Patients}

We retrospectively enrolled 78 patients who had visited hospitals associated with our group (Nagasaki University Hospital, Oita University Hospital, University of Occupational and Environmental Health Hospital, Nagasaki Harbor Medical Center, Nagasaki Medical Center, and Sasebo Chuo Hospital) between 2003 and 2017. Patients with RA fulfilled ACR/EULAR RA criteria 2010 (Aletaha et al. 2010). They included the following: 20 cases of PCP during MTX treatment for RA (MTX-PCP group), 30 cases of MTX-induced interstitial pneumonia in patients with RA (MTX-IP group), 16 cases of RA-IP (RA-IP group), 13 cases of PCP including non-RA patients or RA patients without MTX treatment (PCP group). The PCP group included the following: five patients with malignant tumors undergoing chemotherapy, three cases of non-RA connective tissue disease, two cases with RA but without MTX treatment, two cases with idiopathic interstitial pneumonia, and one case that was human immuno- deficiency virus-positive. PCP was defined based on the following criteria: (1) respiratory symptoms, (2) occurrence of new bilateral infiltrates upon chest radiograph or chest high-resolution computed tomography (HRCT), (3) detection of Pneumocystis jirovecii (P. jirovecii) by traditional staining (Grocott, Diff-Quik or Giemsa staining) or by PCR in respiratory specimens, and (4) significantly elevated plasma $\beta$-D-glucan levels. MTX-PCP was defined by a PCP diagnosis in patients with RA treated with MTX. MTX-IP was defined by the following criteria: (1) patients who were receiving MTX before the onset of respiratory symptoms, (2) occurrence of new bilateral infiltrates upon chest radiograph or HRCT, and (3) exclusion of infection, especially PCP, through intensive diagnostic procedures such as bronchoscopy or examination of sputum, and measurement of plasma $\beta$-D-glucan. RA-IP was defined based on the following: (1) diagnosis of RA, (2) presence of IP detected by HRCT, and (3) absence of infections or drug-induced pneumonia.

The study protocol was approved by the Human Ethics Review Committee at Nagasaki University Hospital, and all participants provided written, informed consent before enrolment.

\section{Data collection}

All data, including arterial blood gas analyses and Krebs von den Lungen 6 (KL-6), a marker of interstitial pneumonia, as well as bronchoalveolar lavage fluid (BALF) findings, were obtained from medical records. Patients were not under treatment for PCP or MTX-IP with systemic steroids and/or immunosuppressants at the time of sample collection. The alveolar-arterial oxygen difference $\left(\mathrm{A}-\mathrm{aDO}_{2}\right)$ was approximated based on the following expected values of the fraction of inspired oxygen in patients without mechanical ventilation: room air $=0.21$; nasal cannula: $1 \mathrm{~L} / \mathrm{min}=0.24,2 \mathrm{~L} / \mathrm{min}=$ $0.28,3 \mathrm{~L} / \mathrm{min}=0.32,4 \mathrm{~L} / \mathrm{min}=0.36,5 \mathrm{~L} / \mathrm{min}=0.40$; mask: $5 \mathrm{~L} / \mathrm{min}$ $=0.40,6 \mathrm{~L} / \mathrm{min}=0.50,7 \mathrm{~L} / \mathrm{min}=0.60$; reservoir mask: $6 \mathrm{~L} / \mathrm{min}=$ $0.60,7 \mathrm{~L} / \mathrm{min}=0.70,8 \mathrm{~L} / \mathrm{min}=0.80,9 \mathrm{~L} / \mathrm{min}=0.90$, and $10 \mathrm{~L} / \mathrm{min}=$ 0.99 (Hara et al. 2011). $\mathrm{PaO}_{2}$ and $\mathrm{PaCO}_{2}$ were measured by the analysis of arterial blood gas.

The HRCT findings were reviewed separately in random order by two independent observers who were not aware of the patients' profiles. The HRCT data were categorized into five previously established patterns (Silva and Muller 2006; Kakugawa et al. 2013; Travis et al. 2013) as follows: (1) hypersensitivity pneumonia (HP), (2) organizing pneumonia (OP), (3) nonspecific interstitial pneumonia, (4) diffuse alveolar damage, and (5) usual interstitial pattern. Following the initial independent evaluations, divergent observations were resolved by consensus after consultation between the two observers. The extent of visual ground glass opacity or consolidation was determined by visually estimating the extent in the upper, middle, and lower zones of each lung based on the percentage of the lung field that showed each abnormality in each zone (estimated to the nearest $10 \%$ of parenchymal involvement) according to the previous reports of Johkoh et al. (2002) and Sumikawa et al. (2006). The upper zone was defined as the area above the level of the carina, the lower zone as the area below the level of the inferior pulmonary vein, and the middle zone as the area between the upper and lower zones. Overall percent involvement was obtained by averaging the six lung zones.

Statistical analysis

All values are expressed as the median and inter-quartile range (IQR). Differences among groups were determined using the 
Kruskal-Wallis test for continuous variables. If a significant difference was found using the Kruskal-Wallis test, multiple comparisons were performed using the Dunn test. Correlations between parameters were determined based on the Spearman's rank correlation coefficient. The upper left corner coordinate point of the receiver operating characteristic (ROC) curve was used to determine the optimum cutoff level to discriminate between the PCP group and the other groups. Statistical significance was defined as $\mathrm{p}<0.05$.

\section{Results}

\section{Patient characteristics}

Patient characteristics are shown in Table 1. Differences in sex, age, and duration of the underlying disease were not significant among groups. The dosage of MTX treatment was similar between MTX-IP and MTX-PCP groups. In addition, there was no significant difference in the fre- quency of corticosteroid or biological agents for underlying diseases among the four groups. Anti-PCP prophylaxis using antibiotic sulfamethoxazole-trimethoprim was performed on only two patients: one PCP patient and one patient with MTX-IP (Table 1).

\section{Laboratory findings}

The laboratory findings of each group are shown in Table 2. No significant differences in white blood cell counts were seen among the groups. Lymphocyte counts and immunoglobulin G levels in PCP and MTX-PCP groups were lower than those in the RA-IP group. C-reaction protein (CRP) and $\mathrm{A}-\mathrm{aDO}_{2}$ in the MTX-PCP group were higher than those in the RA-IP and MTX-IP groups. Lactate dehydrogenase (LDH) in the RA-IP group was lower than that in the other groups. KL-6 was not dif-

Table 1. Subject characteristics.

\begin{tabular}{|c|c|c|c|c|c|}
\hline & $\begin{array}{l}\text { RA-IP } \\
\mathrm{n}=16\end{array}$ & $\begin{array}{c}\text { PCP } \\
\mathrm{n}=13\end{array}$ & $\begin{array}{c}\text { MTX-IP } \\
\mathrm{n}=30\end{array}$ & $\begin{array}{c}\text { MTX-PCP } \\
\mathrm{n}=20\end{array}$ & $\mathrm{p}$ value \\
\hline Male & $6(37.5 \%)$ & $8(61.5 \%)$ & $10(33.3 \%)$ & $7(35.0 \%)$ & $p=0.362$ \\
\hline Age, years & $65(60-75)$ & $66(60-71)$ & $66(62-73)$ & $69(63-77)$ & $\mathrm{p}=0.476$ \\
\hline Underlying disease duration, months & $56(11-107)$ & $14(5-57)$ & $45(13-156)$ & $14(5-82)$ & $\mathrm{p}=0.206$ \\
\hline Lung diseases at baseline & $16(100 \%)$ & $3(23.1 \%)^{*}$ & $8(26.7 \%)^{*}$ & $5(25.0 \%)^{*}$ & $\mathrm{p}<0.001$ \\
\hline \multicolumn{6}{|l|}{ Treatment at onset } \\
\hline Corticosteroid & $6(37.5 \%)$ & $7(53.8 \%)$ & $17(56.7 \%)$ & $14(70.0 \%)$ & $\mathrm{p}=0.298$ \\
\hline Dosage of corticosteroid (mg/day) & $0(0-4.4)$ & $2.5(0.0-20.0)$ & $2.3(0.0-5.0)$ & $2.8(0.0-5.0) 20$ & $\mathrm{p}=0.491$ \\
\hline Methotrexate & $2(12.5 \%)$ & $0(0.0 \%)$ & $30(100 \%)^{*}+\ddagger$ & $(100 \%)^{*}+\ddagger$ & $\mathrm{p}<0.001$ \\
\hline Dosage of methotrexate (mg/week) & $0.0(0.0-0.0)$ & $0.0(0.0-0.0)$ & $10.0(6.0-12.0)^{*},+$ & $9.0(6.0-10.0)^{*}, *$ & $\mathrm{p}<0.001$ \\
\hline Biological agents & $3(18.8 \%)$ & $0(0.0 \%)$ & $10(33.3 \%)$ & $5(25.0 \%)$ & $\mathrm{p}=0.094$ \\
\hline PCP prophylaxis & $0(0.0 \%)$ & $1(7.7 \%)$ & $1(3.0 \%)$ & $0(0.0 \%)$ & $\mathrm{p}=0.508$ \\
\hline 30 days mortality $(\%)$ & $0(0.0 \%)$ & $1(7.7 \%)$ & $0(0.0 \%)$ & $0(0.0 \%)$ & $\mathrm{p}=0.165$ \\
\hline
\end{tabular}

Data are presented as median (interquartile range) or No. (\%).

RA-IP, rheumatoid arthritis-associated interstitial pneumonia; PCP, pneumocystis jiroveccii pneumonia without MTX use; MTX-IP, methothorexate-induced interstitial pneumonia; MTX-PCP, pneumocystis jiroveccii pneumonia during MTX use.

$* \mathrm{p}<0.05$ compared with RA-IP group.

${ }^{\ddagger} \mathrm{p}<0.05$ compared with PCP group.

Table 2. Laboratory findings.

\begin{tabular}{|c|c|c|c|c|c|c|c|c|c|}
\hline & RA-IP & $\mathrm{n}$ & $\mathrm{PCP}$ & $\mathrm{n}$ & MTX-IP & $\mathrm{n}$ & MTX-PCP & $\mathrm{n}$ & $\mathrm{p}$ value \\
\hline $\mathrm{WBC}(/ \mu \mathrm{L})$ & $7,450(4,825-8,750)$ & 16 & $7,400(4,500-12,250)$ & 10 & $7,550(5,525-1,0775)$ & 30 & $9,645(6,325-12,945)$ & 20 & $\mathrm{p}=0.322$ \\
\hline Lymphocytes $(/ \mu \mathrm{L})$ & $1,650(998-2,102)$ & 16 & $650(406-1,365)^{*}$ & 10 & $1,303(854-1,768)$ & 30 & $858(330-1,404)^{*}$ & 18 & $\mathrm{p}=0.004$ \\
\hline $\mathrm{CRP}(\mathrm{mg} / \mathrm{dL})$ & $1.1(0.3-3.7)$ & 16 & $3.7(0.9-7.2)$ & 13 & $2.8(0.7-5.4)$ & 30 & $9.5(6.7-12.3)^{*}, \S$ & 20 & $\mathrm{p}<0.001$ \\
\hline $\operatorname{IgG}(\mathrm{mg} / \mathrm{dL})$ & $1,594(1,343-2,070)$ & 12 & $799(600-1,424)^{*}$ & 6 & $1,212(1,053-1,592)$ & 24 & $906(753-1,268)^{*}$ & 14 & $\mathrm{p}=0.001$ \\
\hline $\mathrm{LDH}(\mathrm{U} / \mathrm{L})$ & $211(161-230)$ & 14 & $387(199-442)^{*}$ & 12 & $300(229-404)^{*}$ & 26 & $315(271-381)^{*}$ & 16 & $\mathrm{p}=0.001$ \\
\hline KL-6 (U/mL) & $438(217-971)$ & 16 & $871(416-1,329)$ & 12 & $729(346-1,144)$ & 29 & $515(331-1,502)$ & 20 & $\mathrm{p}=0.363$ \\
\hline sIL-2R (U/mL) & $744(675-916)$ & 14 & $1,147(681-1,882)$ & 9 & $890(627-1,589)$ & 15 & $4,194(1,450-7,935)^{*}, \downarrow, \S$ & 13 & $\mathrm{p}<0.001$ \\
\hline$\beta$-D-glucan $(\mathrm{pg} / \mathrm{mL})$ & $9(5-12)$ & 13 & $102(49-225)^{*}$ & 13 & $7(3-17)^{*}$ & 29 & $93(40-381)^{*}, \S$ & 18 & $\mathrm{p}<0.001$ \\
\hline $\mathrm{A}-\mathrm{aDO} 2(\mathrm{mmHg})$ & $20.3(4.3-31.5)$ & 12 & $31.3(18.4-81.7)$ & 8 & $40.0(18.8-48.1)$ & 25 & $90.4(52.9-126.9)^{*}, \S$ & 16 & $\mathrm{p}<0.001$ \\
\hline \multicolumn{10}{|l|}{ BALF analysis } \\
\hline Total cell count $\left(10^{\wedge} 5 / \mathrm{mL}\right)$ & $4.5(2.4-6.1)$ & 16 & $4.9(4.0-6.8)$ & 10 & $6.9(3.8-10.8)$ & 20 & $6.2(3.0-10.3)$ & 12 & $\mathrm{p}=0.232$ \\
\hline Macrophages (\%) & $51.1(29.1-79.7)$ & 16 & $40.4(32.0-53.4)$ & 10 & $20.3(14.9-30.5)^{*}$ & 20 & $33.4(15.0-43.6)$ & 12 & $\mathrm{p}=0.001$ \\
\hline Neutrophils (\%) & $6.9(0.9-16.6)$ & 16 & $9.0(2.6-10.6)$ & 10 & $5.0(1.7-11.5)$ & 20 & $11.6(6.5-40.5)$ & 12 & $\mathrm{p}=0.109$ \\
\hline Lymphocytes (\%) & $30.1(15.5-42.0)$ & 16 & $46.9(35.7-62.4)$ & 10 & $60.5(44.6-77.6)^{*}$ & 20 & $36.3(28.1-47.1)^{\S}$ & 12 & $\mathrm{p}=0.002$ \\
\hline Eosinophils (\%) & $1.7(0.9-2.1)$ & 16 & $0.0(0.0-1.3)$ & 10 & $4.5(0.3-5.9)^{\$}$ & 20 & $2.1(0.5-12.9)$ & 12 & $\mathrm{p}=0.029$ \\
\hline $\mathrm{CD} 4 / \mathrm{CD} 8$ ratio & $1.4(0.6-2.2)$ & 16 & $0.7(0.5-1.3)$ & 10 & $2.9(1.6-5.1)^{*}, *$ & 20 & $2.8(1.3-4.7)^{+}$ & 12 & $\mathrm{p}=0.001$ \\
\hline
\end{tabular}

Data are presented as median (interquartile range).

WBC, white blood cells; CRP, C-reactive protein; IgG, immunoglobulin G; LDH, lactate dehydrogenase; KL-6, Krebs von den lungen-6; sIL-2R, soluble interleukin-2 receptor; A-aDO2, alveolar-arterial oxygen difference; BALF, bronchoalveolar lavage fluid.

$* p<0.05$ compared with RA-IP group.

t $<<0.05$ compared with PCP group.

$\S \mathrm{p}<0.05$ compared with MTX-IP group. 


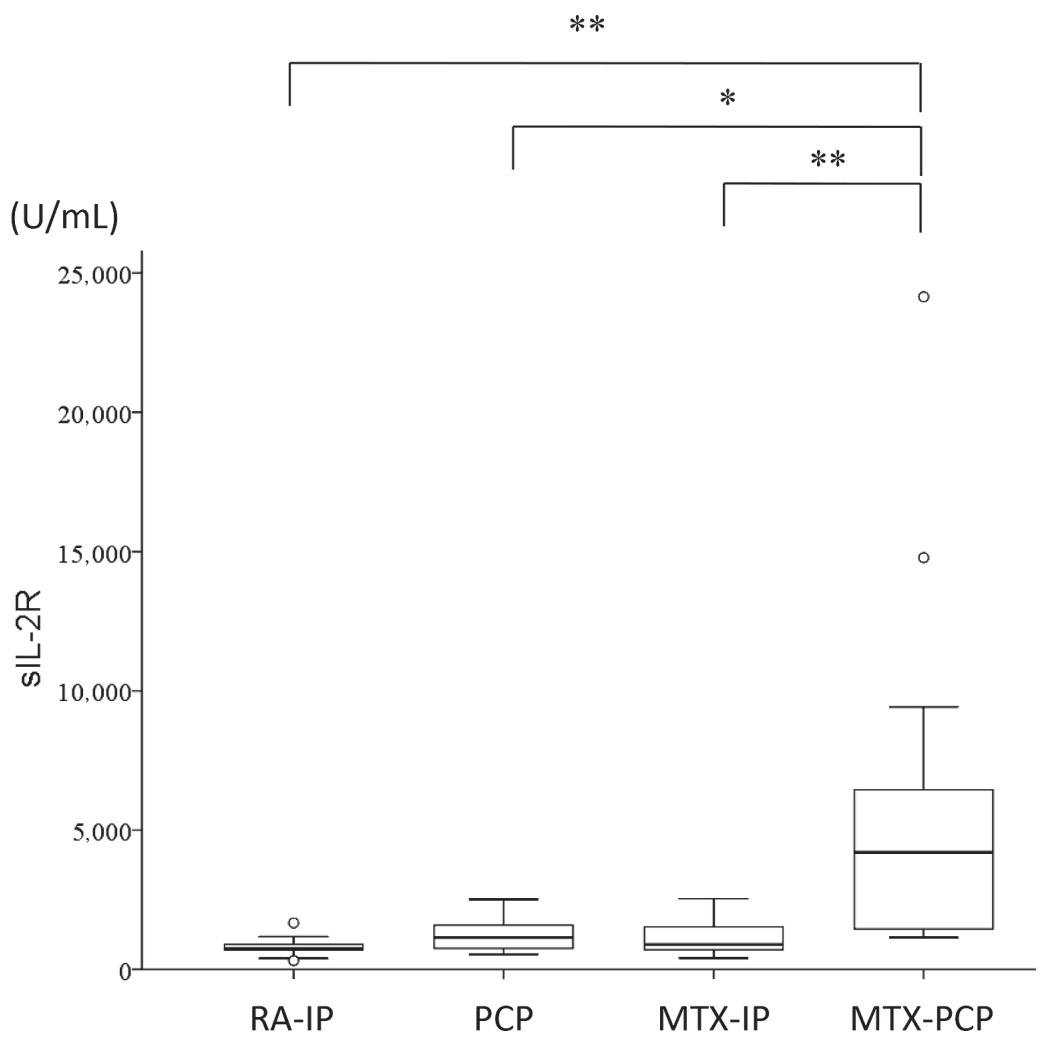

Fig. 1. Serum soluble IL-2 receptor (sIL-2R) levels of patient samples.

Serum sIL-2R levels of the four groups are compared: rheumatoid arthritis (RA)-associated interstitial pneumonia (RAIP), Pneumocystis jirovecii pneumonia without methotrexate treatment (PCP), methotrexate therapy-associated interstitial pneumonia (MTX-IP), and methotrexate therapy-associated Pneumocystis jirovecii pneumonia (MTX-PCP). Boxes represent the IQR, and the internal line represents the median. Whiskers indicate the lowest and highest values within $1.5 \times$ IQR values. The open circle represents the values over boxes and whiskers. $* \mathrm{p}<0.05$. $* * \mathrm{p}<0.01$.

Table 3. HRCT patterns.

\begin{tabular}{lccccc}
\hline & $\begin{array}{c}\text { RA-IP } \\
\mathrm{n}=16\end{array}$ & & $\begin{array}{c}\text { PCP } \\
\mathrm{n}=13\end{array}$ & $\begin{array}{c}\text { MTX-IP } \\
\mathrm{n}=30\end{array}$ & $\begin{array}{c}\text { MTX-PCP } \\
\mathrm{n}=20\end{array}$ \\
\cline { 1 - 2 } \cline { 5 - 6 } HP & $0(0.0 \%)$ & & $10(76.9 \%)$ & $19(63.3 \%)$ & $16(80.0 \%)$ \\
OP & $9(56.3 \%)$ & & $0(0.0 \%)$ & $9(30.0 \%)$ & $0(0.0 \%)$ \\
NSIP & $3(18.8 \%)$ & & $2(15.4 \%)$ & $2(6.7 \%)$ & $2(10.0 \%)$ \\
DAD & $0(0.0 \%)$ & & $1(7.7 \%)$ & $0(0.0 \%)$ & $2(10.0 \%)$ \\
UIP & $4(25.0 \%)$ & & $0(0.0 \%)$ & $0(0.0 \%)$ & $0(0.0 \%)$ \\
\hline
\end{tabular}

Data are presented as No. $(\%)$.

HP, hypersensitivity pneumonia; OP, organizing pneumonia; NSIP, nonspecific interstitial pneumonia; DAD, diffuse alveolar damage; UIP, usual interstitial pneumonia.

ferent among any groups. sIL-2R in the MTX-PCP group was higher than that in the other groups (Fig. 1). BALF findings showed that the percentage of lymphocytes in the MTX-IP group was higher than that in the RA-IP and MTX-PCP groups, whereas the percentage of eosinophils in the MTX-IP group was higher than that in the PCP group. Further, the $\mathrm{CD} 4 / \mathrm{CD} 8$ ratio in the MTX-IP group was higher than that in the RA-IP and PCP groups, whereas the ratio in the MTX-PCP group was higher than that in the PCP group.

\section{HRCT patterns}

Table 3 shows the HRCT patterns of each group. The pattern of hypersensitivity pneumonia (HP) was the most frequent finding among PCP, MTX-IP, and MTX-PCP groups, whereas the RA-IP group predominantly showed the pattern of organizing pneumonia (OP). The OP pattern was the second-most frequent pattern in the MTX-IP group.

\section{Receiver operating characteristic curve}

We next evaluated the sensitivity and specificity of 
serum sIL-2R levels to distinguish the MTX-PCP group from the other groups based on ROC curves. Fig. 2 shows the ROC curves for several markers (A-aDO2, CRP, sIL$2 \mathrm{R}$, and KL-6) in patients of the MTX-PCP group and in the other groups. The areas under the ROC curve (AUC) for A-aDO2, CRP, sIL-2R, and KL-6 were 0.894, 0.856, 0.917 , and 0.539 , respectively. Levels of sIL-2R were more sensitive than other markers and showed the largest AUC. Based on the ROC curve, the cut-off level of sIL-2R that resulted in the highest diagnostic accuracy for MTX-PCP was $1,311.5 \mathrm{U} / \mathrm{mL}$. This value was found to discriminate between the MTX-PCP group and other groups with $91.7 \%$ sensitivity and $78.6 \%$ specificity.
Correlations between $s I L-2 R$ and clinical parameters in each group

To clarify the significance of the observed elevated levels of sIL-2R, correlations between sIL-2R levels and clinical parameters in each group were analyzed (Table 4). Levels of sIL-2R in the MTX-IP group showed significant positive correlations with the dosage of MTX treatment and $\beta$-D-glucan levels and negative correlations with $\operatorname{IgG}$ and the percentage of macrophages in the BALF. In contrast, levels of sIL-2R in the MTX-PCP group showed a significant positive correlation with the value of $\mathrm{A}-\mathrm{aDO} 2$. In addition, levels of sIL-2R in the RA-IP group showed a significant positive correlation with CRP and negative correlations with the percentage of macrophages and the percent-

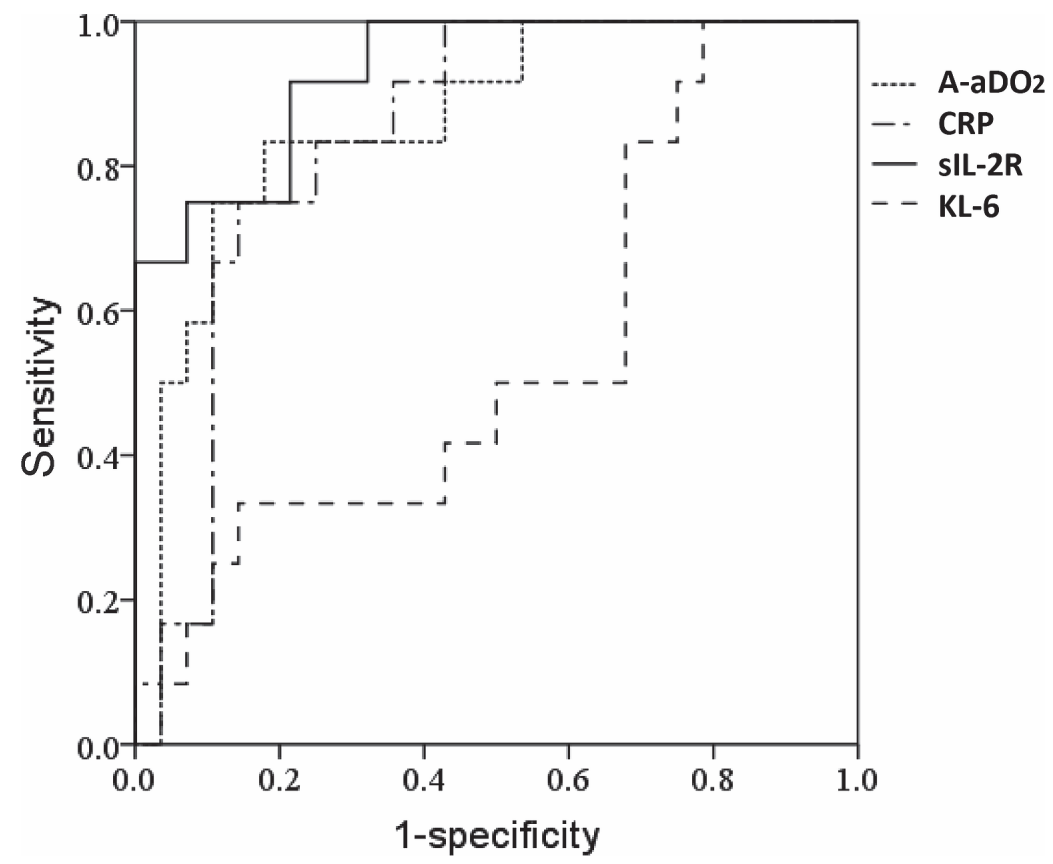

Fig. 2. Receiver operating characteristic curve for parameters in patients with MTX-associated PCP.

The cut-off level of soluble IL-2 receptor (sIL-2R) that resulted in the highest diagnostic accuracy for the MTX-associated PCP (MTX-PCP) group was 1,311.5 U/ml. This value was found to discriminate between the MTX-PCP group and the other groups with $91.7 \%$ sensitivity and $78.6 \%$ specificity. The use of serum sIL-2R levels for the diagnosis of MTX-PCP resulted in the largest area under the curve (AUC, 0.917) when compared to that based on A-aDO2, CRP, and KL-6.

Table 4. Correlation between sIL-2R and clinical parameters.

\begin{tabular}{|c|c|c|c|c|c|c|c|c|c|c|c|c|c|c|c|c|}
\hline \multirow[t]{2}{*}{ Variables } & \multicolumn{4}{|c|}{ sIL-2R with RA-IP } & \multicolumn{4}{|c|}{ sIL-2R with PCP } & \multicolumn{4}{|c|}{ sIL-2R with MTX-IP } & \multicolumn{4}{|c|}{ sIL-2R with MTX-PCP } \\
\hline & III & & $95 \% \mathrm{CI}$ & p value & $\mathrm{n}$ & $\mathrm{r}$ & $95 \% \mathrm{CI}$ & $p$ value & $\mathrm{n}$ & $\mathrm{r}$ & $95 \% \mathrm{CI}$ & $\mathrm{p}$ value & $\mathrm{n}$ & $\mathrm{r}$ & $95 \% \mathrm{CI}$ & p value \\
\hline Dosage of corticosteroid (mg/day) & 14 & 0.264 & $-0.310-0.697$ & 0.362 & 9 & -0.376 & $-0.832-0.384$ & 0.319 & 15 & 0.038 & $-0.484-0.540$ & 0.894 & 13 & -0.363 & $-0.762-0.235$ & 0.223 \\
\hline Dosage of MTX (mg/week) & 14 & -0.378 & $-0.757-0.191$ & 0.182 & 0 & . & 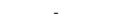 & 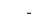 & 14 & 0.571 & $0.058-0.845$ & 0.033 & 13 & -0.539 & $-0.840-0.017$ & 0.057 \\
\hline Laboratory data & & & & & & & & & & & & & & & & \\
\hline WBC $(/ \mu \mathrm{L})$ & 14 & 0.293 & $-0.281-0.713$ & 0.310 & 9 & -0.183 & $-0.755-0.548$ & 0.637 & 15 & 0.159 & $-0.385-0.621$ & 0.571 & 13 & -0.308 & $-0.734-0.293$ & 0.306 \\
\hline $\mathrm{CRP}(\mathrm{mg} / \mathrm{dL})$ & 14 & 0.744 & $0.353-0.914$ & 0.002 & 9 & 0.583 & $-0.132-0.899$ & 0.025 & 15 & 0.093 & $-0.440-0.578$ & 0.742 & 13 & 0.371 & $0.128-0.708$ & 0.212 \\
\hline $\mathrm{IgG}(\mathrm{mg} / \mathrm{dL})$ & 11 & 0.045 & $-0.570-0.628$ & 0.894 & 6 & -0.543 & $-0.940--0.480$ & 0.266 & 13 & -0.560 & $-0.849--0.013$ & 0.046 & 12 & -0.371 & $-0.779-0.258$ & 0.235 \\
\hline $\mathrm{LDH}(\mathrm{U} / \mathrm{L})$ & 13 & -0.225 & $-0.690-0.372$ & 0.459 & 9 & 0.561 & $-0.164-0.893$ & 0.116 & 13 & -0.159 & $-0.653-0.430$ & 0.603 & 9 & -0.133 & $-0.732-0.583$ & 0.732 \\
\hline $\mathrm{KL}-6(\mathrm{U} / \mathrm{mL})$ & 11 & -0.420 & $-0.815-0.241$ & 0.135 & 9 & -0.383 & $-0.835-0.377$ & 0.308 & 15 & -0.129 & $-0.602-0.410$ & 0.648 & 13 & -0.096 & $-0.614-0.480$ & 0.754 \\
\hline$\beta$-D-glucan $(\mathrm{pg} / \mathrm{mL})$ & 12 & 0.559 & $-0.022-0.858$ & 0.059 & 9 & 0.233 & $-0.510-0.777$ & 0.546 & 15 & 0.671 & $0.242-0.881$ & 0.006 & 13 & 0.212 & $-0.384-0.683$ & 0.531 \\
\hline $\mathrm{A}-\mathrm{aDO} 2(\mathrm{mmHg})$ & 10 & -0.030 & $-0.647-0.611$ & 0.934 & 7 & 0.143 & $-0.684-0.809$ & 0.760 & 11 & 0.036 & $-0.576-0.622$ & 0.915 & 12 & 0.608 & $0.052-0.876$ & 0.036 \\
\hline HRCT score & 13 & 0.999 & $0.999-0.999$ & 0.746 & 9 & 0.400 & $-0.360-0.841$ & 0.286 & 14 & 0.341 & $-0.231-0.738$ & 0.233 & 10 & -0.159 & $-0.717-0.523$ & 0.622 \\
\hline BALF cell fin & & & & & & & & & & & & & & & & \\
\hline Total cell count $\left(\times 10^{5} / \mathrm{mL}\right)$ & 14 & 0.143 & $-0.419-0.626$ & 0.626 & 7 & 0.464 & $-0.444-0.902$ & 0.294 & 15 & 0.018 & $-0.499-0.525$ & 0.950 & 8 & -0.095 & $-0.749-0.653$ & 0.823 \\
\hline Macrophages (\%) & 14 & -0.543 & $-0.833--0.017$ & 0.045 & 7 & -0.714 & $-0.954-0.085$ & 0.071 & 15 & -0.525 & $-0.817--0.017$ & 0.044 & 8 & -0.643 & $-0.927-0.113$ & 0.086 \\
\hline Lymphocytes (\%) & 14 & 0.265 & $-0.309-0.698$ & 0.418 & 7 & 0.893 & $0.427-0.718$ & 0.007 & 15 & 0.325 & $-0.225-0.718$ & 0.237 & 8 & -0.214 & $-0.798-0.578$ & 0.610 \\
\hline Neutrophils (\%) & 14 & -0.543 & $-0.833-0.017$ & 0.039 & 7 & -0.714 & $-0.525-0.984$ & 0.071 & 15 & -0.018 & $-0.525-0.499$ & 0.950 & 8 & 0.286 & $-0.524-0.825$ & 0.493 \\
\hline Eosinophils (\%) & 14 & 0.473 & $-0.077-0.802$ & 0.088 & 7 & 0.079 & $-0.717-0.785$ & 0.867 & 15 & -0.065 & $-0.559-0.463$ & 0.818 & 8 & 0.683 & $-0.042-0.937$ & 0.062 \\
\hline CD4/CD8 (\%) & 14 & 0.341 & $-0.231-0.738$ & 0.233 & 7 & 0.250 & $-0.620-0.844$ & 0.589 & 15 & 0.389 & $-0.154-0.752$ & 0.152 & 8 & 0.190 & $-0.594-0.789$ & 0.651 \\
\hline
\end{tabular}

WBC, white blood cells; CRP, C-reactive protein; IgG, immunoglobulin G; LDH, lactate dehydrogenase; KL-6, Krebs von den lungen-6; sIL-2R, soluble interleukin-2 receptor; A-aDO2, alveolar-arterial oxygen difference; HRCT, high-resolution computed tomography; BALF, bronchoalveolar lavage fluid. 
age of neutrophils in the BALF.

\section{Discussion}

The present study showed elevated levels of serum sIL-2R in patients with PCP during MTX treatment for RA compared to those in MTX-IP and RA-IP groups, as well as in patients with PCP without MTX treatment. These diseases are important and difficult to distinguish in RA patients treated with MTX. This is the first report to show that serum sIL-2R could be a marker to discriminate MTXPCP from MTX-IP.

Serum sIL-2R levels have been reported as a disease marker of RA. Serum sIL-2R levels were found to be related to disease duration (Tebib et al. 1995), and a decline in sIL-2R concentration might result from joint improvement (Rubin et al. 1990). It has been reported that sIL-2R levels are significantly reduced in RA patients receiving a low dose of MTX (Polisson et al. 1994; Spadaro et al. 1997). In addition, baseline and serial serum sIL-2R levels in patients with sarcoidosis correlate with improvements in lung function during MTX treatment (Vorselaars et al. 2015). These results suggest that sIL-2R represents the activity of RA, and that MTX treatment usually inhibits $\mathrm{T}$ cell activation and decreases sIL-2R levels in RA patients.

In contrast, it has also been reported that serum sIL-2R levels are increased in acquired immunodeficiency syndrome (AIDS) patients with PCP (Reddy and Grieco 1988). In the present study, serum sIL-2R levels were higher in all groups, suggesting that $\mathrm{T}$ cells were activated to some degree in RA-IP, PCP, MTX-IP, and MTX-PCP groups. However, serum sIL-2R levels were significantly higher in the MTX-PCP group compared with those in other groups. Furthermore, ROC curve analysis demonstrated that sIL-2R had the highest AUC discriminating between the MTX-PCP group and the other groups. These results suggest that serum sIL-2R levels could be a candidate marker to distinguish MTX-PCP from other diseases. We further analyzed the correlation between sIL-2R levels and clinical parameters to determine the pathogenesis of increased SIL-2R levels in each group. Serum levels of sIL-2R in the MTX-PCP group were significantly correlated with $\mathrm{A}-\mathrm{aDO} 2$ values. This indicates that levels of sIL-2R correspond to disease severity in MTX-PCP.

We next sought an explanation for the observed higher levels of sIL-2R in the MTX-PCP group compared with those in other groups. Higher levels of sIL-2R in the MTXPCP group, as compared with those in the PCP group, suggest that $\mathrm{T}$ cells in the lungs are more activated by PCP in response to MTX treatment, rather than PCP alone. It has been reported that MTX induces the apoptosis of activated T cells (Genestier et al. 1998) and that short-term MTX treatment reduces peripheral $\mathrm{T}$ cells in RA patients (Wascher et al. 1994). In contrast, long-term treatment with MTX significantly increases CD3+ and CD4+ peripheral $\mathrm{T}$ cells (Weinblatt et al. 1988). CD4+ T cells play a pivotal role in the pathogenesis of PCP (Hoving and Kolls 2017).
In an animal model of PCP, CD25-CD4+ T cells were found to induce acute lethal pneumonia, whereas CD25+CD4+ T cells have been suggested to be recruited to the lungs to suppress hyper-inflammation driven by PCP (Hori et al. 2002; McKinley et al. 2006). These reports might indicate that CD25-CD4+ T cells activated by MTX treatment for RA excessively responded to PCP and cause hyper-inflammation, whereas CD25+CD4+ T cells, the source of sIL-2R, might protect the lung from hyper-inflammation and result in increased sIL-2R levels in MTX-PCP. This is consistent with a report that PCP in non-AIDS patients is associated with smaller numbers of PCP organisms and a greater number of inflammatory cells in the BALF compared to those in AIDS patients (Limper et al. 1989). Recently, Shimada et al. (2018) reported the differences in PCP between patients with RA and other connective tissue diseases. They reported that almost all PCP in RA patients receiving MTX alone was $P$. jirovecii PCRnegative in respiratory specimens and associated with higher CRP levels suggesting that small amounts of $P$. jirovecci induce stronger inflammation in RA patients receiving MTX alone. Based on the previous report (Shimada et al. 2018) and the present study, synergistic factors including MTX therapy, the existence of $P$. jirovecii, and RA itself might induce severe inflammation resulting in higher serum sIL-2R levels in the MTX-PCP group.

The present study has several limitations. First, the study cohort was small, and the design was retrospective. Second, the diagnosis of PCP was mainly based on elevated levels of $\beta$-D-glucan and the detection of $P$. jirovecii by PCR. Although $\beta$-D-glucan is a useful serological marker for PCP diagnosis (Li et al. 2015; Song et al. 2016), colonization by $P$. jirovecii, as detected by a PCR method, has also been reported (Alanio and Bretagne 2017). Mori et al. (2009) reported that $10.9 \%$ of asymptomatic carriers of $P$. jirovecii could be identified by PCR using the sputum or BALF of patients with RA, all of whom had received MTX. These results suggest that the MTX-PCP group in the present study might include the individuals colonized by $P$. jirovecii. Further prospective studies with more precise diagnostic criteria for PCP will be needed to clarify the role of serum sIL-2R in MTX-PCP.

Overall, our study demonstrates that MTX-PCP is associated with increased systemic inflammation, severe hypoxemia, and higher sIL-2R levels, as compared with those in MTX-IP cases. Further, serum sIL-2R levels could be useful for the differential diagnosis of MTX-PCP and MTX-IP, which otherwise have similar characteristics.

\section{Acknowledgments}

We acknowledge the patients and staff who participated in our research studies.

\section{Conflicts of Interest}

The authors declare no conflict of interest. 


\section{References}

Alanio, A. \& Bretagne, S. (2017) Pneumocystis jirovecii detection in asymptomatic patients: what does its natural history tell us? F1000Res., 6, 739.

Aletaha, D., Neogi, T., Silman, A.J., Funovits, J., Felson, D.T., Bingham, C.O. 3rd, Birnbaum, N.S., Burmester, G.R., Bykerk, V.P., Cohen, M.D., Combe, B., Costenbader, K.H., Dougados, M., Emery, P., Ferraccioli, G., et al. (2010) 2010 Rheumatoid arthritis classification criteria: an American College of Rheumatology/European League Against Rheumatism collaborative initiative. Arthritis Rheum., 62, 2569-2581.

Chan, E.S. \& Cronstein, B.N. (2002) Molecular action of methotrexate in inflammatory diseases. Arthritis Res., 4, 266-273.

Chodorowska, G., Czelej, D. \& Niewiedziol, M. (2003) Interleukin-2 and its soluble receptor in selected drug-induced cutaneous reactions. Ann. Univ. Mariae Curie Sklodowska Med., 58, 7-13.

Genestier, L., Paillot, R., Fournel, S., Ferraro, C., Miossec, P. \& Revillard, J.P. (1998) Immunosuppressive properties of methotrexate: apoptosis and clonal deletion of activated peripheral T cells. J. Clin. Invest., 102, 322-328.

Hara, S., Ishimoto, H., Sakamoto, N., Mukae, H., Kakugawa, T., Ishimatsu, Y., Mine, M. \& Kohno, S. (2011) Direct hemoperfusion using immobilized polymyxin B in patients with rapidly progressive interstitial pneumonias: a retrospective study. Respiration; international review of thoracic diseases, $\mathbf{8 1}$, 107-117.

Hashimoto, A., Suto, S., Horie, K., Fukuda, H., Nogi, S., Iwata, K., Tsuno, H., Ogihara, H., Kawakami, M., Komiya, A., Furukawa, H., Matsui, T. \& Tohma, S. (2017) Incidence and Risk Factors for Infections Requiring Hospitalization, Including Pneumocystis Pneumonia, in Japanese Patients with Rheumatoid Arthritis. Int. J. Rheumatol., 2017, 6730812.

Hori, S., Carvalho, T.L. \& Demengeot, J. (2002) CD25+CD4+ regulatory $\mathrm{T}$ cells suppress $\mathrm{CD} 4+\mathrm{T}$ cell-mediated pulmonary hyperinflammation driven by Pneumocystis carinii in immunodeficient mice. Eur. J. Immunol., 32, 1282-1291.

Hoving, J.C. \& Kolls, J.K. (2017) New advances in understanding the host immune response to Pneumocystis. Curr. Opin. Microbiol., 40, 65-71.

Johkoh, T., Muller, N.L., Colby, T.V., Ichikado, K., Taniguchi, H., Kondoh, Y., Fujimoto, K., Kinoshita, M., Arakawa, H., Yamada, H., Suga, M., Ando, M., Koyama, M. \& Nakamura, H. (2002) Nonspecific interstitial pneumonia: correlation between thin-section CT findings and pathologic subgroups in 55 patients. Radiology, 225, 199-204.

Kakugawa, T., Yokota, S., Ishimatsu, Y., Hayashi, T., Nakashima, S., Hara, S., Sakamoto, N., Matsuoka, Y., Kubota, H., Mine, M., Mukae, H., Nagata, K. \& Kohno, S. (2013) Serum heat shock protein 47 levels in patients with drug-induced lung disease. Respir. Res., 14, 133.

Li, W.J., Guo, Y.L., Liu, T.J., Wang, K. \& Kong, J.L. (2015) Diagnosis of pneumocystis pneumonia using serum (1-3)-beta-DGlucan: a bivariate meta-analysis and systematic review. $J$. Thorac. Dis., 7, 2214-2225.

Limper, A.H., Offord, K.P., Smith, T.F. \& Martin, W.J. 2nd (1989) Pneumocystis carinii pneumonia. Differences in lung parasite number and inflammation in patients with and without AIDS. Am. Rev. Respir. Dis., 140, 1204-1209.

Lopez-Olivo, M.A., Siddhanamatha, H.R., Shea, B., Tugwell, P., Wells, G.A. \& Suarez-Almazor, M.E. (2014) Methotrexate for treating rheumatoid arthritis. Cochrane Database Syst. Rev., CD000957.

McKinley, L., Logar, A.J., McAllister, F., Zheng, M., Steele, C. \& Kolls, J.K. (2006) Regulatory T cells dampen pulmonary inflammation and lung injury in an animal model of pneumocystis pneumonia. J. Immunol., 177, 6215-6226.
Mori, S., Cho, I. \& Sugimoto, M. (2009) A followup study of asymptomatic carriers of Pneumocystis jiroveci during immunosuppressive therapy for rheumatoid arthritis. J. Rheumatol., 36, 1600-1605.

Norton, S., Koduri, G., Nikiphorou, E., Dixey, J., Williams, P. \& Young, A. (2013) A study of baseline prevalence and cumulative incidence of comorbidity and extra-articular manifestations in RA and their impact on outcome. Rheumatology (Oxford), 52, 99-110.

Polisson, R.P., Dooley, M.A., Dawson, D.V. \& Pisetsky, D.S. (1994) Interleukin-2 receptor levels in the sera of rheumatoid arthritis patients treated with methotrexate. Arthritis Rheum., 37, 50-56.

Reddy, M.M. \& Grieco, M.H. (1988) Elevated soluble interleukin-2 receptor levels in serum of human immunodeficiency virus infected populations. AIDS Res. Hum. Retroviruses, 4, 115-120.

Richman, N.C., Yazdany, J., Graf, J., Chernitskiy, V. \& Imboden, J.B. (2013) Extraarticular manifestations of rheumatoid arthritis in a multiethnic cohort of predominantly Hispanic and Asian patients. Medicine (Baltimore), 92, 92-97.

Rubin, L.A. \& Nelson, D.L. (1990) The soluble interleukin-2 receptor: biology, function, and clinical application. Ann. Intern. Med., 113, 619-627.

Rubin, L.A., Snow, K.M., Kurman, C.C., Nelson, D.L. \& Keystone, E.C. (1990) Serial levels of soluble interleukin 2 receptor in the peripheral blood of patients with rheumatoid arthritis: correlations with disease activity. J. Rheumatol., 17, 597-602.

Shimada, K., Yokosuka, K., Nunokawa, T. \& Sugii, S. (2018) Differences in clinical Pneumocystis pneumonia in rheumatoid arthritis and other connective tissue diseases suggesting a rheumatoid-specific interstitial lung injury spectrum. Clin. Rheumatol., 37, 2269-2274.

Silva, C.I. \& Muller, N.L. (2006) Drug-induced lung diseases: most common reaction patterns and corresponding high-resolution CT manifestations. Semin. Ultrasound CT MR, 27, 111-116.

Singh, J.A., Saag, K.G., Bridges, S.L. Jr., Akl, E.A., Bannuru, R.R., Sullivan, M.C., Vaysbrot, E., McNaughton, C., Osani, M., Shmerling, R.H., Curtis, J.R., Furst, D.E., Parks, D., Kavanaugh, A., O’Dell, J., et al. (2016) 2015 American College of Rheumatology Guideline for the Treatment of Rheumatoid Arthritis. Arthritis Rheumatol., 68, 1-26.

Smolen, J.S., Landewe, R., Bijlsma, J., Burmester, G., Chatzidionysiou, K., Dougados, M., Nam, J., Ramiro, S., Voshaar, M., van Vollenhoven, R., Aletaha, D., Aringer, M., Boers, M., Buckley, C.D., Buttgereit, F., et al. (2017) EULAR recommendations for the management of rheumatoid arthritis with synthetic and biological disease: modifying antirheumatic drugs: 2016 update. Ann. Rheum. Dis., 76, 960-977.

Song, Y., Ren, Y., Wang, X. \& Li, R. (2016) Recent advances in the diagnosis of pneumocystis pneumonia. Med. Mycol. J., 57, E111-E116.

Spadaro, A., Taccari, E., Riccieri, V., Sensi, F., Sili Scavalli, A. \& Zoppini, A. (1997) Relationship of soluble interleukin2 -receptor and interleukin-6 with class-specific rheumatoid factors during low-dose methotrexate treatment in rheumatoid arthritis. Rev. Rhum. Engl. Ed., 64, 89-94.

Sumikawa, H., Johkoh, T., Ichikado, K., Taniguchi, H., Kondoh, Y., Fujimoto, K., Tateishi, U., Hiramatsu, T., Inoue, A., Natsag, J., Ikemoto, M., Mihara, N., Honda, O., Tomiyama, N., Hamada, S., et al. (2006) Usual interstitial pneumonia and chronic idiopathic interstitial pneumonia: analysis of CT appearance in 92 patients. Radiology, 241, 258-266.

Takahashi, S., Setoguchi, Y., Nukiwa, T. \& Kira, S. (1991) Soluble interleukin-2 receptor in sera of patients with pulmonary tuberculosis. Chest, 99, 310-314.

Tanaka, H., Narita, M., Teramoto, S., Saikai, T., Oashi, K., 
Igarashi, T. \& Abe, S. (2002) Role of interleukin-18 and T-helper type 1 cytokines in the development of Mycoplasma pneumoniae pneumonia in adults. Chest, 121, 1493-1497.

Tebib, J.G., Letroublon, M.C., Noel, E., Bienvenu, J. \& Bouvier, M. (1995) sIL-2R levels in rheumatoid arthritis: poor correlation with clinical activity is due in part to disease duration. $\mathrm{Br}$. J. Rheumatol., 34, 1037-1040.

Thi Hong Nguyen, C., Kambe, N., Kishimoto, I., Ueda-Hayakawa, I. \& Okamoto, H. (2017) Serum soluble interleukin-2 receptor level is more sensitive than angiotensin-converting enzyme or lysozyme for diagnosis of sarcoidosis and may be a marker of multiple organ involvement. J. Dermatol., 44, 789-797.

Travis, W.D., Costabel, U., Hansell, D.M., King, T.E. Jr., Lynch, D.A., Nicholson, A.G., Ryerson, C.J., Ryu, J.H., Selman, M., Wells, A.U., Behr, J., Bouros, D., Brown, K.K., Colby, T.V., Collard, H.R., et al. (2013) An official American Thoracic Society/European Respiratory Society statement: update of the international multidisciplinary classification of the idiopathic interstitial pneumonias. Am. J. Respir. Crit. Care Med., 188, 733-748.

Turka, L.A. \& Walsh, P.T. (2008) IL-2 signaling and CD4+ CD25+ Foxp3+ regulatory T cells. Front. Biosci., 13, 1440-
1446.

Vorselaars, A.D., van Moorsel, C.H., Zanen, P., Ruven, H.J., Claessen, A.M., van Velzen-Blad, H. \& Grutters, J.C. (2015) $\mathrm{ACE}$ and sIL-2R correlate with lung function improvement in sarcoidosis during methotrexate therapy. Respir. Med., 109, 279-285.

Wascher, T.C., Hermann, J., Brezinschek, H.P., Brezinschek, R., Wilders-Truschnig, M., Rainer, F. \& Krejs, G.J. (1994) Celltype specific response of peripheral blood lymphocytes to methotrexate in the treatment of rheumatoid arthritis. Clin. Investig., 72, 535-540.

Weinblatt, M.E., Trentham, D.E., Fraser, P.A., Holdsworth, D.E., Falchuk, K.R., Weissman, B.N. \& Coblyn, J.S. (1988) Longterm prospective trial of low-dose methotrexate in rheumatoid arthritis. Arthritis Rheum., 31, 167-175.

Witkowska, A.M. (2005) On the role of sIL-2R measurements in rheumatoid arthritis and cancers. Mediators Inflamm., 2005, 121-130.

Zou, Y.Q., Li, Y.S., Ding, X.N. \& Ying, Z.H. (2012) The clinical significance of HRCT in evaluation of patients with rheumatoid arthritis-associated interstitial lung disease: a report from China. Rheumatol. Int., 32, 669-673. 